\title{
Non-ceremonial tobacco use among southwestern rural American Indians: the New Mexico American Indian Behavioural Risk Factor Survey
}

\author{
Frank D Gilliland, Renate Mahler, Sally M Davis
}

Abstract

Objectives-To ascertain non-ceremonial tobacco use among rural American Indians in New Mexico (United States). Design-A geographically targeted telephone survey.

Setting-Rural New Mexico.

Participants-American Indian residents aged 18 years and older.

Main outcome measures-Prevalence of ever-smokers and current smokers of cigarettes and ever-users and current users of smokeless tobacco, number of cigarettes smoked, and prevalence of cigarette smoking quitting behaviour.

Results-Of the 1266 respondents, $38.5 \%$ $(95 \%$ confidence interval $(\mathrm{CI})=34.5 \%$ to $42.1 \%$ ) reported ever smoking, and $16.3 \%$ $(95 \% \mathrm{CI}=13.5 \%$ to $19.0 \%)$ reported being current smokers. Current smokers averaged $7.6(95 \% \mathrm{CI}=6.0$ to 9.3$)$ cigarettes per day. Current smoking prevalence was highest among men and lowest among college graduates. Prevalence of smokeless tobacco use was $24.1 \%$ for ever-use and $7.2 \%$ for current use and showed a strong male predominance of use.

Conclusions-The prevalence of current smokers among rural American Indians in New Mexico was lower than among American Indians of other regions in the United States, all New Mexicans, and the national population as a whole. Although smoking prevalence was lower among American Indians in New Mexico, variation by sex and education followed the same patterns as reported among American Indians of other regions. (Tobacco Control 1998;7:156-160)

Department of Internal Medicine, New Mexico Tumor Registry,

Epidemiology and

Cancer Control

Program, University of

New Mexico Health

Sciences Center,

Albuquerque, New

Mexico, USA

F D Gilliland

R Mahler

Prevention Center, University of New

Mexico Health

Sciences Center

S M Davis

Correspondence to: Dr FD Gilliland, 900

Camino de Salud NE

Albuquerque, New Mexico

87131, USA

fgillila@medusa.unm.edu Keywords: American Indians, tobacco use, smokeless tobacco

\section{Introduction}

Tobacco use is an important health risk behaviour for cancer, ${ }^{1-6}$ non-malignant respiratory disease, and cardiovascular disease. ${ }^{1-8}$ Smoking is the leading cause of preventable death, accounting for more than 400000 deaths in $1990 .{ }^{9}$ Surveillance of tobacco use is an essential component of health promotion and disease prevention programmes. smoking and tobacco use among American Indians have been hampered by inadequate surveillance data about tobacco use. The primary surveillance tool in New Mexico has been the Behavioural Risk Factor Surveillance System (BRFSS), ${ }^{10}$ a national surveillance system that uses telephone interviews to identify risk factors associated with chronic disease, including both cigarette and smokeless tobacco use. Although the proportion of American Indians included in the national BRFSS data appears to be representative, ${ }^{11}$ data for New Mexico show an under-representation of American Indians. American Indians comprise $8.9 \%$ of the New Mexico population, but from 1986-1995 the BRFSS interviewed only 319 American Indians, which represents $2.6 \%$ of the total interviews. Reasons for this under-representation include telephone noncoverage; under-sampling in rural areas, where most New Mexico American Indians reside; and possible cultural biases in the survey instrument.

To conduct a more comprehensive investigation of the prevalence of tobacco use among rural New Mexico American Indians aged 18 years and older, we developed the American Indian Behavioural Risk Factor Survey (AIBRFS), which adapted the national BRFSS for use with the American Indian population. The objectives of the survey were to estimate the prevalence of non-ceremonial tobacco use, including smokeless tobacco; and to describe tobacco use patterns by age, sex, and educational attainment.

\section{Methods}

Our survey, the AIBRFS, was administered by telephone to 1275 rural New Mexico American Indians aged 18 years and older residing throughout the state of New Mexico. The survey focused on rural communities because $88 \%$ of the New Mexico American Indian population reside in rural areas. ${ }^{12}$

The AIBRFS used an 80-item questionnaire

In New Mexico, interventions to control adapted from the BRFSS, a national surveillance system administered by the US Centers for Disease Control and Prevention, for the telephone interviews. Although questionnaire items were worded exactly as on the BRFSS, the introduction, question order, and transitional phrases of the questionnaire were adapted for use with the rural American Indian community, based on input from an American Indian advisory committee. Question items about tobacco use were distinguished as "non-ceremonial tobacco use". The questions addressed ever and current use of cigarettes and smokeless tobacco, number of cigarettes smoked, and quitting behaviour. 
Table 1 AIBRFS 1995-1997 respondent characteristics compared with 1990 United States census data for American Indians residing in New Mexico

\begin{tabular}{|c|c|c|c|}
\hline \multirow[b]{2}{*}{ Variable } & \multicolumn{2}{|c|}{$\begin{array}{l}\text { AIBRFS } \\
\text { respondents } \\
(n=1266)\end{array}$} & \multirow{2}{*}{$\begin{array}{l}\text { Census data } \\
(n=80074) \%\end{array}$} \\
\hline & $n$ & $\%$ & \\
\hline \multicolumn{4}{|l|}{ Age } \\
\hline $18-24$ & 208 & 16.4 & 20.1 \\
\hline $25-34$ & 317 & 25.0 & 29.5 \\
\hline $35-44$ & 315 & 24.9 & 20.7 \\
\hline $45-54$ & 211 & 16.7 & 12.6 \\
\hline $55-64$ & 135 & 10.7 & 8.2 \\
\hline$\geqslant 65$ & 80 & 6.3 & 8.8 \\
\hline \multicolumn{4}{|l|}{ Sex } \\
\hline Male & 441 & 34.8 & 47.3 \\
\hline Female & 825 & 65.2 & 52.7 \\
\hline \multicolumn{4}{|l|}{ Education } \\
\hline$<9$ th grade & 121 & 9.6 & 17.4 \\
\hline 9 th -11 th grade & 129 & 10.2 & 23.3 \\
\hline High-school graduate & 412 & 32.5 & 32.4 \\
\hline Some college & 411 & 32.5 & 21.9 \\
\hline College graduate & 193 & 15.2 & 4.9 \\
\hline \multicolumn{4}{|l|}{ Income } \\
\hline$<\$ 10 \mathrm{~K}$ & 113 & 9.8 & 42.1 \\
\hline$\$ 10-<15 \mathrm{~K}$ & 134 & 11.6 & 14.2 \\
\hline$\$ 15-<25 \mathrm{~K}$ & 389 & 33.8 & 19.5 \\
\hline$\$ 25-<35 \mathrm{~K}$ & 234 & 20.3 & 11.4 \\
\hline$\$ 35-<50 \mathrm{~K}$ & 175 & 15.2 & 8.2 \\
\hline$\$ 50-<75 \mathrm{~K}$ & 78 & 6.8 & 3.7 \\
\hline$\$ \geqslant 75 \mathrm{~K}$ & 29 & 2.5 & 0.9 \\
\hline Refused/unknown & 114 & $\mathrm{ND}$ & $\mathrm{ND}$ \\
\hline \multicolumn{4}{|l|}{ Tribe } \\
\hline Navajo & & 54.0 & 61.5 \\
\hline Pueblo & & 28.2 & 26.9 \\
\hline Apache/other & & 17.8 & 11.6 \\
\hline
\end{tabular}

AIBRFS $=$ American Indian Behavioral Risk Factor Survey. $\mathrm{ND}=$ no data

Data were collected by computer-aided telephone interviewing (CATI) and paperand-pencil recording methods. Because data from a commercial survey firm indicated that relatively few (18.9\%) of rural New Mexico numbers were unlisted (unpublished data, Survey Sampling Inc.), we used published household telephone samples that targeted general geographical areas to increase the efficiency of our sample. We defined rural areas as including all areas of New Mexico except Ber-

Table 2 Non-ceremonial cigarette tobacco use by age, sex, and education among rural American Indians of New Mexico, AIBRFS 1995-1997

\begin{tabular}{|c|c|c|c|c|c|c|}
\hline \multirow[b]{2}{*}{ Variable } & \multicolumn{2}{|c|}{$\begin{array}{l}\text { Ever-smokers } \\
(n=449)\end{array}$} & \multicolumn{2}{|c|}{$\begin{array}{l}\text { Current smokers } \\
(n=188)\end{array}$} & \multicolumn{2}{|c|}{$\begin{array}{l}\text { Number of cigarettes } \\
\text { per day among current } \\
\text { smokers }\end{array}$} \\
\hline & $\%^{*}$ & $95 \% C I$ & $\%^{*}$ & $95 \% C I$ & Mean* & $95 \% C I$ \\
\hline \multicolumn{7}{|l|}{ Aget } \\
\hline $18-24$ & 37.8 & $30.6-45.0$ & 20.7 & $14.4-27.0$ & 6.6 & $2.7-10.5$ \\
\hline $25-34$ & 32.1 & $25.2-38.9$ & 11.8 & $7.1-16.4$ & 8.3 & $4.1-12.5$ \\
\hline $35-44$ & 37.1 & $30.6-43.7$ & 19.5 & $13.7-25.3$ & 6.6 & $4.4-8.8$ \\
\hline $45-54$ & 49.6 & $39.6-59.6$ & 11.4 & $5.7-17.0$ & 4.8 & $3.1-6.4$ \\
\hline $55-64$ & 52.8 & $40.3-65.2$ & 21.9 & $11.6-32.2$ & 10.2 & $5.6-14.6$ \\
\hline$\geqslant 65$ & 35.5 & $19.9-51.0$ & 15.3 & $3.3-27.3$ & 12.2 & $5.1-19.3$ \\
\hline \multicolumn{7}{|l|}{ Sex $\neq S$} \\
\hline Male & 52.0 & $46.0-57.9$ & 21.2 & $16.3-26.1$ & 7.2 & $5.1-9.4$ \\
\hline Female & 26.3 & $22.6-30.1$ & 11.8 & $9.2-14.4$ & 8.3 & $5.7-10.8$ \\
\hline \multicolumn{7}{|l|}{ Education } \\
\hline$<9$ th grade & 45.8 & $34.4-57.1$ & 18.5 & $9.7-27.2$ & 6.4 & $2.9-10.0$ \\
\hline 9 th-11th grade & 37.3 & $27.8-46.9$ & 18.3 & $11.2-25.3$ & 8.5 & $4.0-13.0$ \\
\hline $\begin{array}{l}\text { High-school } \\
\text { graduate }\end{array}$ & 37.2 & $32.1-42.3$ & 15.6 & $11.7-19.6$ & 9.0 & $6.1-11.9$ \\
\hline Some college & 36.6 & $31.4-41.7$ & 14.7 & $11.0-18.4$ & 6.1 & $4.3-7.9$ \\
\hline College graduate & 34.7 & $31.4-38.0$ & 9.9 & $4.3-15.6$ & 3.9 & $1.2-6.7$ \\
\hline Overalls & 38.5 & $34.8-42.1$ & 16.3 & $13.5-19.0$ & 7.6 & $6.0-9.3$ \\
\hline
\end{tabular}

*Weighted by age, sex, and education distribution of New Mexican Indians from 1990 United States census.

†Significant variation by age for $\%$ ever-smoked, Wald $\chi^{2}=11.90, \mathrm{df}=5, \mathrm{p}=0.0368$.

$\ddagger$ Significant variation by sex for $\%$ ever-smoked, Wald $\chi^{2}=47.51, \mathrm{df}=1, \mathrm{p}<0.0001$

\Significant variation by sex for $\%$ currently smoking, Wald $\chi^{2}=10.89, \mathrm{df}=1, \mathrm{p}=0.0010$.

AIBRFS $=$ American Indian Behavioral Risk Factor Survey.

$\mathrm{CI}=$ confidence intervals. nalillo County, Doña Ana County, and the City of Santa Fe. Quality control activities included standardised interviewer training, onsite supervision, and verification callbacks to a random sample of 60 survey respondents within 10 days of the initial telephone interview to monitor the authenticity and accuracy of the interviews.

All data were edited, coded, and combined into one data set for analysis with SAS (version 6.12) and SUDAAN (release 7.0) software. ${ }^{13-14}$ The response rate was calculated using the Council of American Survey Research Organization formula, which apportions call dispositions with unknown eligibility status to dispositions in the same proportions as those existing among calls of known status. The calculated response rate for the survey was $74.0 \%$. The sample of respondents included an over-representation of women, people with college education, and people with an annual household income over $\$ 15000$, when compared with the general population of American Indians aged 18 years and older in New Mexico (table 1). Therefore, survey results were adjusted to the age, sex, and education distribution of American Indians in New Mexico from the 1990 United States census. Age categories were 18-24, 25-34, 35-44, $45-54,55-64$, and 65 years and older. Education was categorised as less than ninth grade, ninth to 11 th grade, high school graduate, some college, or college graduate. (Ages are typically $14-15$ years for ninth grade, 15-16 years for 10th grade, and so on.) Sample weights were computed as the inverse of the sample fraction for each age/sex/education category. Education information was missing for two respondents and cigarette use was unknown for seven. All proportions and means were computed on the remaining 1266 respondents.

\section{Results}

SAMPLE REPRESENTATIVENESS

To ascertain whether the sample of New Mexico American Indians identified through the AIBRFS reflected the characteristics of this population as identified through the 1990 census, we made comparisons by age, sex, educational attainment, income, and tribe (table 1). The age distribution and tribal affiliation of the survey respondents reflected those of the 1990 census, but gender, income, and education distributions were different.

CIGARETTE SMOKING

Smoking was not common among rural American Indians in New Mexico. The prevalence of ever-smokers (100 cigarettes or more in their lifetime), which includes current smokers, was $38.5 \%$; the prevalence for current smokers was $16.3 \%$ (table 2). Men were more likely than women to have ever smoked, and to be current smokers of cigarettes. Lower educational attainment was associated with a higher prevalence of current or ever-smoking. Those aged 45-64 had a higher prevalence of ever-smoking compared with those aged less than 45 years. Current 
Table 3 Non-ceremonial smokeless tobacco use by age, sex, and education among rural American Indians of New Mexico, AIBRFS 1995-1997

\begin{tabular}{|c|c|c|c|c|}
\hline & \multicolumn{2}{|c|}{$\begin{array}{l}\text { Ever used smokeless tobacco } \\
(n=223)\end{array}$} & \multicolumn{2}{|c|}{$\begin{array}{l}\text { Currently use smokeless } \\
\text { tobacco }(n=56)\end{array}$} \\
\hline & $\% *$ & $95 \% C I$ & $\%^{*}$ & $95 \% C I$ \\
\hline \multicolumn{5}{|l|}{ Aget‡ } \\
\hline $18-24$ & 24.9 & $18.4-31.5$ & 7.9 & $3.6-12.2$ \\
\hline $25-34$ & 31.1 & $23.9-38.3$ & 7.9 & $3.4-12.3$ \\
\hline $35-44$ & 25.8 & $19.2-32.5$ & 8.8 & $4.2-13.4$ \\
\hline $45-54$ & 17.5 & $7.7-27.3$ & 7.4 & $0.0-15.4$ \\
\hline $55-64$ & 14.9 & $5.5-24.3$ & 5.6 & $0.0-11.8$ \\
\hline$\geqslant 65$ & 12.7 & $0.9-24.4$ & 0.6 & $0.0-1.7$ \\
\hline \multicolumn{5}{|l|}{$\operatorname{Sex} \coprod^{\star \star}$} \\
\hline Male & 43.9 & $38.0-49.9$ & 13.6 & $9.4-17.9$ \\
\hline Female & 6.3 & $4.0-8.6$ & 1.4 & $0.0-2.7$ \\
\hline \multicolumn{5}{|l|}{ Educationt† } \\
\hline$<9$ th grade & 23.5 & $13.3-33.7$ & 7.3 & $0.7-13.8$ \\
\hline 9th-11th grade & 24.8 & $15.4-34.1$ & 8.9 & $2.7-15.0$ \\
\hline High-school graduate & 25.0 & $20.1-29.8$ & 8.9 & $5.6-12.1$ \\
\hline Some college & 24.4 & $19.6-29.2$ & 3.8 & $1.5-6.0$ \\
\hline College graduate & 15.5 & $9.3-21.7$ & 2.5 & $0.0-5.0$ \\
\hline Overall & 24.1 & $20.7-27.5$ & 7.2 & $5.0-9.4$ \\
\hline
\end{tabular}

*Weighted by age, sex, and education distribution of New Mexican Indians from 1990 United States census.

†Significant variation by age for $\%$ ever-used, Wald $\chi^{2}=12.49, \mathrm{df}=5, \mathrm{p}=0.0292$.

$\ddagger$ Significant variation by age for $\%$ currently using, Wald $\chi^{2}=17.23, \mathrm{df}=5, \mathrm{p}=0.0043$.

\Significant variation by sex for $\%$ ever-used, Wald $\chi^{2}=118.29, \mathrm{df}=1, \mathrm{p}<0.0001$.

$\star \star$ Significant variation by sex for $\%$ currently using, Wald $\chi^{2}=28.42, \mathrm{df}=1, \mathrm{p}<0.0001$.

$\dagger+$ Significant variation by education for $\%$ currently using, Wald $\chi^{2}=12.04, \mathrm{df}=4, \mathrm{p}=0.0174$.

AIBRFS $=$ American Indian Behavioral Risk Factor Survey.

$\mathrm{CI}=$ confidence intervals.

cigarette smoking did not show a consistent pattern with increasing age, although younger respondents tended to have higher prevalences of current smoking.

Current smokers averaged 7.6 cigarettes smoked per day. Older respondents tended to smoke more cigarettes per day than younger respondents. Among current smokers who reported smoking cigarettes each of the 30 days before our survey, 20 (45.5\%) estimated that they smoke between 1-5 cigarettes per day, nine $(20.5 \%)$ estimated $6-10$ cigarettes per day, $10(22.7 \%)$ estimated $11-20$ cigarettes per day, and five $(11.3 \%)$ reported more than 20 cigarettes per day.

Of the 188 current smokers, 70 smoked fewer than 30 days out of the past 30, 115 smoked on each of the 30 days, and information was missing for three. Of the 115 who smoked every day, 58 reported that they had stopped smoking for at least one day in the past 12 months; the unweighted proportion is $50.4 \%$, and the proportion for the population is $56.3 \%$.

Of the 261 former smokers, 102 had stopped within the past five years, 137 had stopped more than five years ago, 13 were never regular smokers, and information was missing for nine. The crude proportion of respondents who stopped within the past five years was $40.5 \%$ and the weighted proportion for the population is $43.5 \%$.

SMOKELESS TOBACCO USE

About a quarter of the rural American Indian population had ever used smokeless tobacco (table 3). Younger respondents and men were more likely to have ever used smokeless tobacco or to be current users. Individuals with some college education had a lower prevalence of current use.

\section{Discussion}

Giovino et al reported a nationwide decrease in the prevalence of tobacco use, but found the prevalence to be higher for cigarette smoking, non-cigarette tobacco smoking, and smokeless tobacco use among American Indians, Alaska Natives, and non-Hispanic blacks compared with Hispanics and Asians/Pacific Islanders. ${ }^{15}$ Other researchers have also reported a high prevalence of tobacco use among some American Indian groups. ${ }^{16-23}$ Regional differences for cigarette smoking prevalence were reported in 1968 by Sievers, ${ }^{24}$ who reported that smoking was lower among American Indians in southwestern states than among those of other regions.

According to our findings, cigarette smoking prevalence is lower among rural New Mexico American Indians compared with American Indians of other regions, the general New Mexico population, and the American population as a whole. Our survey results show that $16.3 \%$ of rural New Mexico American Indians currently smoke cigarettes. The prevalence of cigarette smoking is estimated to be $25.7 \%$ for the American population, $19.6 \%$ for all New Mexicans, and $42.2 \%$ for American Indians and Alaska Natives nationwide. ${ }^{15}$

Although our findings show a lower prevalence of cigarette smoking for rural New Mexico American Indians than for American Indians nationwide, all New Mexicans, and the American population overall, we found trends by age and sex to be similar to those reported by other researchers. The prevalence of ever-users of cigarettes was lower in the younger age groups, but the prevalence of current use tended to be higher among the young. However, among current smokers of cigarettes, the number of cigarettes smoked was lower among younger persons: a mean of 6.6 cigarettes per day in the youngest age group compared with 12.2 cigarettes per day in the oldest age group. This suggests that interventions need to be targeted toward older as well as young American Indians.

We observed a substantial difference in the prevalence of ever-smokers and current smokers between American Indian men and women, with the prevalence of ever-smoking and current smoking among men double that for women. However, the prevalence of current smoking among rural New Mexico American Indian men $(21.2 \%)$ is lower than for all men nationwide $(28.8 \%)$, and for all American Indian men $(53.7 \%){ }^{25}$

The prevalence of smokeless tobacco use among rural New Mexico American Indians is higher than the national prevalence and the prevalence among New Mexicans overall. We found that $7.2 \%$ of rural New Mexico American Indians currently use smokeless tobacco, a figure higher than the overall prevalence of $4.4 \%$ nationwide and $3.3 \%$ in New Mexico. ${ }^{15}$ We found significant differences in prevalence of smokeless tobacco use by age, sex, and educational attainment. The highest prevalence was in the young age groups for current users $(7.2 \%)$ and ever-users $(24.1 \%)$ of smokeless tobacco. Other investigators have 
also found a higher prevalence of smokeless tobacco use among young American Indians. ${ }^{26-33}$ In a national survey Glover et al reported that $17 \%$ of American Indian college students had used smokeless tobacco, ${ }^{34}$ and Hoover et al found that 33\% of Canadian native children between the ages of seven and 21 were current users. ${ }^{27}$ Smokeless tobacco use is particularly prevalent among young American Indians in the northwestern ${ }^{18-30}$ and southeastern $^{20-28}$ United States. In 1990, Bruerd found smokeless tobacco use to be prevalent at a rate of $55.9 \%$ among young New Mexico American Indians in the ninth and 10 th grades, ${ }^{28}$ which is higher than our findings for those aged 18 years and older in the rural New Mexico American Indian population.

Prevalence of smokeless tobacco use was higher among men than among women in New Mexico. Similar findings have also been reported by other researchers investigating the prevalence of smokeless tobacco use among American Indians. ${ }^{15-30}$ Smokeless tobacco use was also associated with educational attainment; prevalence of current use among high school graduates was $8.9 \%$ compared with $2.5 \%$ for college graduates.

Regional differences have been reported for smokeless tobacco use among American Indians. Smokeless tobacco use was found to be particularly prevalent among Alaska Natives and Canadian American Indians. ${ }^{16-31}$ Yet documentation of both cigarette smoking and smokeless tobacco use among southwestern American Indian tribes, including those of New Mexico, has been limited. Our survey findings parallel those published by Sievers in 1968, which reported the prevalence of smoking to be lower among southwestern American Indians than among those of other regions. ${ }^{24}$ We lack data to allow us to explain the heterogeneity in smoking behaviours among ethnic groups in New Mexico or among American Indian tribes.

Our ability to interview 1266 rural New Mexico American Indians about tobacco use in the AIBRFS telephone survey at a rate of approximately one completed interview per hour indicates that it is possible to collect timely data on tobacco use for this population. These data allow us to measure progress toward achieving health objectives such as Healthy People 2000, ${ }^{35}$ and to assess the impact of interventions targeting rural New Mexico American Indians.

Despite the efficiency of the AIBRFS telephone survey with rural New Mexico American Indians, our research is subject to methodological limitations. The AIBRFS sample differed from the United States census data for New Mexico American Indians in sex (our sample contained more women than men), income level, and educational attainment. Our sample over-represented respondents with an annual household income over $\$ 15000$, and those with an educational attainment of more than a high-school diploma. We adjusted our survey results to reflect the published demographic characteristics of New Mexico American Indians, but the adjustment had sur- prisingly little effect on the survey results. However, validation studies are needed among rural New Mexico American Indians to evaluate the magnitude of potential biases of our telephone research methodology. Pearson et $a l^{36}$ and Peterson et al ${ }^{18}$ conducted validation studies of their telephone surveys with American Indians to determine the potential effect of telephone non-coverage bias, and found that respondents with telephones may differ in their health risk behaviours from those of comparable socioeconomic groups without household telephones. In addition, because of small sample sizes in various demographic subgroups, we could not stratify data by multiple demographic factors to examine possible differences in tobacco use prevalence among these subgroups.

Smoking prevalence among rural American Indians remains lower than for American Indians residing in other regions of the United States and among the general population of New Mexico. Ever-smoking and current smoking were almost twice as prevalent among males than among females. Older smokers appear to be at higher risk because they report a higher mean number of cigarettes smoked per day. Targeted interventions are needed to maintain the generally low proportion of smokers in this population and to increase cessation among men and older smokers.

This research was supported by the US Centers for Disease Control and Prevention through a core grant awarded to the University of New Mexico Center For Health Promotion In American Indian Communities. We thank Jacqueline Two Feathers and Felicia Garcia for interviewing research respondents. We also thank the anonymous reviewers for their helpful comments.

1 Waldum HL, Nilsen OG, Nilsen T, et al. Long-term effects of inhaled nicotine. Life Sci 1996;58:1339-46.

2 Boyle P, Maisonneuve P. Lung cancer and tobacco smoking. Lung Cancer 1995;12:167-81.

3 Kardinal CG. Cancer. A potentially preventable disease. $\mathcal{F}$ LA State Med Soc 1995;147:147-8.

4 Siemiatychi J, Krewski D, Franco E, et al. Associations between cigarette smoking and each of 21 types of cancer: a multi-site case-control study. Int $f$ Epidemiol 1995; 24:504-14

5 Parkin DM, Pisani P, Lopez AD, et al. At least one in seven cases of cancer is caused by smoking. Global estimates for 1985. Int 7 Cancer 1994;59:494-504.

6 Vineis P, Caparaso N. Tobacco and cancer: epidemiology and the laboratory. Environ Health Perspect 1995;103:15660

7 Leone A. Cigarette smoking and cardiovascular damage: analytic review of the subject. Singapore Med $\mathcal{f} 1994$; 35:492-4.

8 Leone A. Cigarette smoking and health of the heart. $\mathcal{F}$ Soc Health 1995;115:354-5.

9 McGinnis JM, Foege WH. Actual causes of death in the United States. $\mathcal{F A M A}$ 1993;270:2207-12.

10 US Centers for Disease Control and Prevention, National Center for Chronic Disease Prevention and Health Promotion. Behavioral Risk Factor Surveillance System. Atlanta, Georgia: CDC, 1982.

11 Sugarman JR, Warren CW, Oge L, et al. Using the Behavioral Risk Factor Surveillance System to monitor year 2000
objectives among American Indians. Public Health Rep objectives among

12 US Bureau of the Census. Census of the population 1990: general population characteristics. Final report. New Mexico. Washington, DC: US Government Printing Office, 1990.

13 SAS Institute, Inc. SAS/STAT user's guide, version 6, 4th edition. Cary, North Carolina: SAS Institute, 1989.

14 Shah BV, Barnwell BG, Bieler GS. SUDAAN user's manual, release 7.0. Research Triangle Park, North Carolina: Research Triangle Institute, 1996.

15 Giovino GA, Schooley MW, Zhu BP, et al. Surveillance for selected tobacco-use behaviors-United States, 19001994. MMWR CDC Surveillance Summary 1994;43:1-43.

16 Beauvais F, Oetling ER, Wolf W, et al. American Indian youth and drugs, 1976-87: a continuing problem. Am $\mathcal{F}$ Public Health 1989;79:634-6.

17 Millar WJ. Place of birth and ethnic status: factors associated with smoking prevalence among Canadians. Health Rep 1992;4:7-24. 
18 Peterson DE, Remington PL, Kuykendall MA, et al. Behavioral risk factors of Chippewa Indians living on Wisconsin
reservations. Public Health Rep 1994;109:820-3.

19 Goldberg HI, Warren CW, Oge LL, et al. Prevalence of behavioral risk factors in two American Indian population in Montana. Am F Prev Med 1991;7:155-60.

20 US Centers for Disease Control. Smokeless tobacco use among American Indian women-southeastern North Carolina. MMWR 1991;44:113-7.

21 Beauvais F. Comparison of drug use rates for reservation Indian, non-reservation Indian, and Anglo youth. Am Indian Alsk Native Ment Health Res 1992;5:13-31.

22 Hodge FS, Cummings S, Fredericks L, et al. Prevalence of smoking among adult American Indian clinic users in Northern California. Prev Med 1995;24:441-6.

23 Bashur R, Quick R. Health attitudes and behaviors of Native Alaskans. Arctic Med Res 1991;(suppl):313-9.

24 Sievers ML. Cigarette and alcohol usage by southwestern American Indians. Am f Public Health 1968;58:71-82.

25 US Centers for Disease Control and Prevention. Cigarette smoking among adults-United States, 1994. MMWR smoking among

26 Peterson JS, Barreto LA, Brunnemann KD. Smokeless tobacco: a product of the new generation of tobacco users. Dipping and chewing in the Northwest Territories, Canada, and its global relevance. Arctic Med Res 1990;49:32-8.

27 Hoover J, McDermott R, Hartsfield T. The prevalence of smokeless tobacco use in native children in northern Saskatchewan, Canada. Can f Public Health 1990;81:350-2.

28 Bruerd B. Smokeless tobacco use among Native American school children. Public Health Rep 1990;105:196-201.
29 Riley WT, Barenie JT, Mabe PA, et al. The role of race and ethnic status on the psychosocial correlates of smokeless tobacco use in adolescent males. If Adolesc Health 1991;12:15-21

30 Hall RL, Dexter D. Smokeless tobacco use and attitudes toward smokeless tobacco among Native Americans and other adolescents in the northwest. Am 7 Public Health 1988; 78:1586-8.

31 Schinke SP, Schilling RF, Gilchrist LD, et al. Pacific northwest Native American youth and smokeless tobacco use. Int $\mathcal{F}$ Addict 1987;22:881-4.

32 Riley WT, Barenie JT, Mabe PA, et al. Smokeless tobacco use in adolescent females: prevalence and psychosocial factors among racial/ethnic groups. F Behav Med 1990; 13:207-20.

33 Millar WJ. Smokeless tobacco use by youth in the Canadian Arctic. Arctic Med Res 1990;49:39-47.

34 Glover ED, Loflin M, Flannery D, et al. Smokeless tobacco use among American college students. $\mathcal{F}$ Am Coll Health 1989;38:81-5.

35 US Public Health Service. Healthy people 2000: national health promotion and disease prevention objectives-full report with commentary. Washington, DC: US Government Printing Office, 1991. (DHHS Publication No (PHS) 91-50212.)

36 Pearson D, Chealde A, Wagner E, et al. Differences in sociodemographic, health status, and lifestyle characteristics among American Indians by telephone coverage. Prev Med 1994;23:461-4.

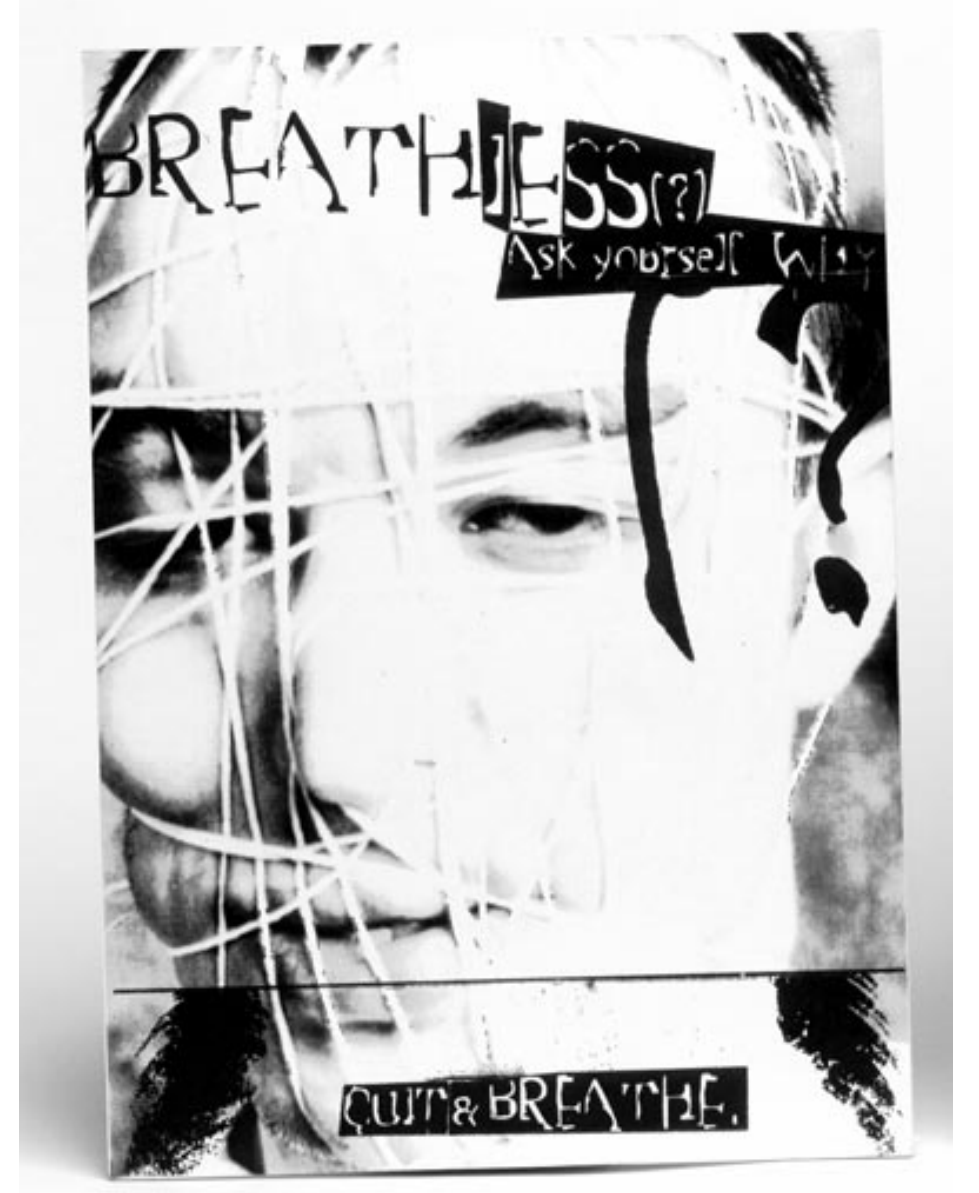

From the University of Central England gallery of anti-tobacco artwork, produced in conjunction with the Smoke Free Birmingham campaign (see cover essay in this issue of "Tobacco Control"). 